\title{
Alkaline Detergent Recycling Via Ultrafiltration
}

\author{
C. Steffani \\ M. Meltzer
}

June 1995

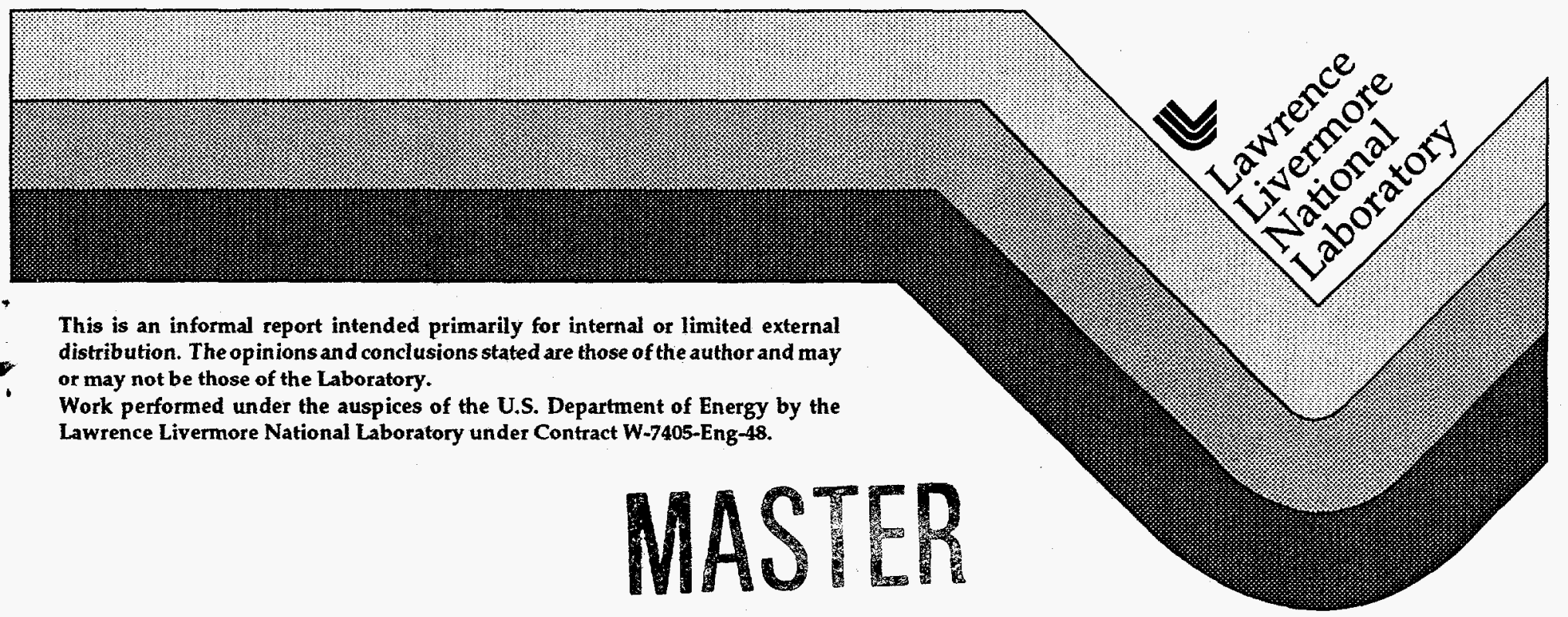

DISTRIBUTION OF THIS DOCUMENT IS UNLIMITED $B S$ 


\section{DISCLAIMER}

This document was prepared as an account of work sponsored by an agency of the United States Government. Neither the United States Government nor the University of California nor any of their employees, makes any warranty, express or implied, or assumes any legal liability or responsibility for the accuracy, completeness, or usefulness of any information, apparatus, product, or process disclosed, or represents that its use would not infringe privately owned rights. Reference herein to any specific commercial product, process, or service by trade name, trademark, manufacturer, or otherwise, does not necessarily constitute or imply its endorsement, recommendation, or favoring by the United States Government or the University of California. The views and opinions of authors expressed herein do not necessarily state or reflect those of the United States Government or the University of California, and shall not be used for advertising or product endorsement purposes.

This report has been reproduced directly from the best available copy.

Available to DOE and DOE contractors from the Office of Scientific and Technical Information P.O. Box 62, Oak Ridge, TN 37831

Prices available from (615) 576-8401, FTS 626-8401

Available to the public from the National Technical Information Service

U.S. Department of Commerce 5285 Port Royal Rd.,

Springfield, VA 22161 


\section{DISCLAIMER}

Portions of this document may be illegible in electronic image products. Images are produced from the best available original document. 


\author{
Alkaline Detergent Recycling Via Ultrafiltration \\ by \\ Chris Steffani \\ Senior Engineering Associate \\ Manufacturing and Materials Engineering Division \\ Lawrence Livermore National Laboratory
}

The metal finishing industry uses alkaline cleaners and detergents to remove oils and dirt from manufactured parts, often before they are painted or plated. The use of these cleaners has grown because environmental regulations are phasing out ozone depleting substances and placing restrictions on the use and disposal of many hazardous solvents.

With use, these alkaline cleaning solutions become contaminated with suspended oils and dirt, which inhibit cleaning power. This floating debris is skimmed from solution surfaces and detergent or caustic is added as make up to maintain cleaning strength. The skimming extends solution life, but the cleaner must still be discarded eventually as contaminant levels build up. If the solution life were extended even further, waste generation and input material costs could be cut.

Lawrence Livermore National Laboratory (LLNL) is examining "ultrafiltration"-a cleaning approach that takes the place of skimming. Ultrafiltration can reclaim spent cleaning solutions and minimize waste. The ultrafiltration membrane is made from sheets of polymerized organic film. The sheets are rolled onto a supporting frame and installed in a tube or other housing. Spent cleaning solution is pumped into a filter chamber and filtered through the membrane that captures oils and dirt and allows water and detergent to pass. A controller monitors the pressure across the membrane. When pressure builds from oil and dirt, an automatic system cleans the surface to maintain solution flow and filtration quality. The results show that the ultrafiltration does not disturb the detergent concentration or alkalinity but removed almost all the oils and dirt.

The system can also be set to clean manually or turned off. It is easy to operate, and the quality of the separation is good. Table 1 shows data collected from the system's trial run. 
Table 1 . Trial run of ultrafiltration system.

\begin{tabular}{|l|l|l|l|}
\hline \multicolumn{2}{|c|}{ Cleaner in solution before separation } & Cleaner in solution after separation \\
\hline Detergent & $65.0 \mathrm{gm} / 1$ & Detergent & $61.0 \mathrm{gm} / 1$ \\
\hline Alkalinity & $0.84 \mathrm{~N}$ & Alkalinity & $0.83 \mathrm{~N}$ \\
\hline Suspended oils & $3.5 \mathrm{gm} / 1$ & Suspended oils & $0.14 \mathrm{gm} / 1$ \\
\hline Suspended solids & $5.0 \mathrm{gm} / 1$ & Suspended solids & $0.04 \mathrm{gm} / 1$ \\
\hline
\end{tabular}

In our trial run, we pumped a total of 150 gallons of spent cleaning solution from the cleaning tank to the ultrafiltration chamber via an inlet hose. However, because the chamber has just a 2-quart capacity, we could filter only a small amount of the 150 gallons at one time. The filtered solvent was pumped back to the cleaning tank via an outlet hose. In the tank, it mixed with the remaining uncleaned detergent, diluting it. We then pumped this diluted mixture to the filter chamber, repeating the ultrafiltration process until the diluted solvent was clean. Because the cleaned detergent continued to be diluted with soiled detergent each time it was recycled back to the cleaning tank, the filtering process took 32 hours to complete. During this time, the initial solution flow through the membrane slowed from 1.1 to 0.4 gallons per minute (gpm), with an average flow of $0.7 \mathrm{gpm}$.

In our second run, we will pump all of the soiled detergent directly from the cleaning tank to a holding tank, then through an inlet hose to the ultrafiltration chamber (see Figure 1). After filtration, it will be pumped back to the cleaning tank through the outlet hose. In that configuration, when we pump each 2 quarts of filtered and cleaned detergent from the filter chamber back to the tank, it will not be diluted by the remaining soiled detergent and slow down the recycling process. Once the entire solution is in the holding tank, we estimate that cleaning will take only about 4 hours. 


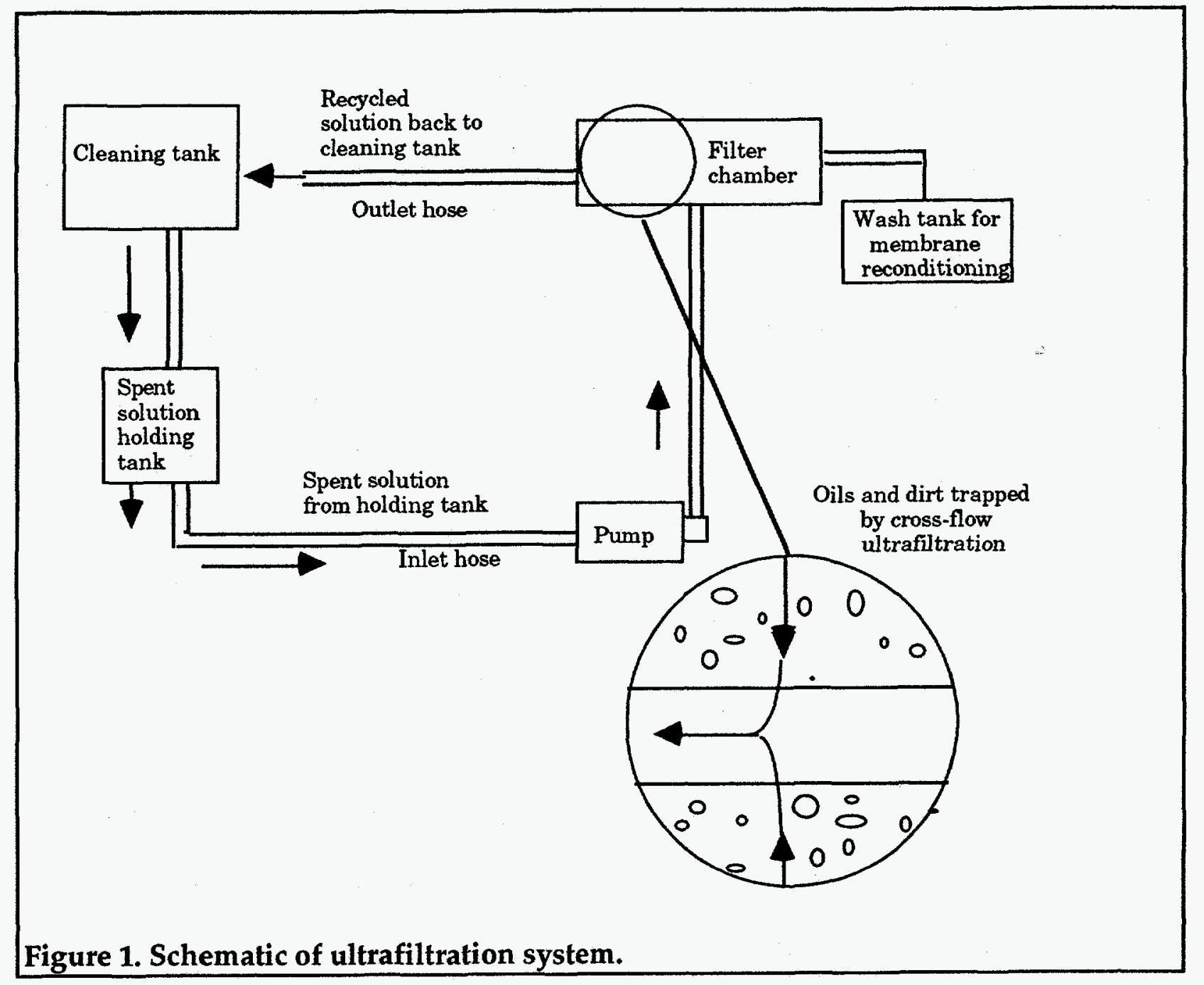

Our studies show that ultrafiltration also might recover synthetic cutting and cooling fluids from machine shop waste. After filtering out oils, the fluids could be reused instead of discarded. We are presently evaluating this approach. 